\title{
Efficiency comparison of ozonation, photolysis, photocatalysis and photoelectrocatalysis methods in real textile wastewater decolorization
}

\author{
Juliano Carvalho Cardoso*, Guilherme Garcia Bessegato, Maria Valnice Boldrin Zanoni \\ Department of Analytical Chemistry, Institute of Chemistry, Universidade Estadual Paulista "Júlio de Mesquita Filho" - UNESP, Av. Prof. Francisco Degni, 55, \\ 14800-060, Araraquara, SP, Brazil
}

\section{A R T I C L E I N F O}

\section{Article history:}

Received 6 January 2016

Received in revised form

28 March 2016

Accepted 3 April 2016

Available online 5 April 2016

\section{Keywords:}

Annular bubble reactor

Photoelectrocatalysis

Ozonation

$\mathrm{TiO}_{2}$ nanotube arrays

Textile effluent

Decolorization

\begin{abstract}
A B S T R A C T
Treatment of real effluents from industries using AOPs stands to be an imperative task of crucial importance yet quite huge a challenge largely given the nature of complexity of these wastewaters. The present work sought to develop a versatile system aimed at the treatment of real wastewater using a bubbling annular reactor, which enables us to test the efficiency of photolysis; photocatalysis, photoelectrocatalysis and direct ozonation using oxygen or ozone as gas flow. $\mathrm{A} \mathrm{TiO}_{2}$ nanotubes electrode was used as photocatalyst in photocatalytic and photoelectrocatalytic measurements with and without coupling with ozonation under $\mathrm{pH} 3.0$ and $\mathrm{pH} 8.0$ leading to 50\% of color removal after 60 min reaction. However, the results indicated $90 \%$ of color removal upon the bubbling of ozone after 15 min of treatment. A synergistic effect was observed in all experiments using the AOPs in the presence of ozone under both $\mathrm{pH}$ values. Interestingly though, $85 \%$ of decolorization was obtained through direct ozonation without any change in the effluent following $10 \mathrm{~min}$ of treatment. The results were discussed in terms of electric energy per order and were compared to those reported previously. For real textile wastewater, ozonation appears to be a promising candidate for full-scale effluent decolorization.
\end{abstract}

(c) 2016 Elsevier Ltd. All rights reserved.

\section{Introduction}

The last decades have witnessed a dramatic surge in interest in water and wastewater treatment as a way to protect the environment and human health. Nonetheless, in the last few years, huge attention has been given to the development, extension and advancement of new approaches, ideas or designs focusing on the efficiency enhancement of well-known technologies or reducing costs/other disadvantages by merging them with cheaper, sustainable and more environmentally friendly methods. The advanced oxidation processes (AOPs) being considered here are among the recent developments regarding water treatment with a wide range of application (Glaze et al., 1987).

One of the greatest challenges of this century lies in efficiency improvement of the treatment of dye wastewater from textile and dyestuff industries. About $200 \mathrm{~L}$ of water are used to produce $1 \mathrm{~kg}$ of textile (Ghaly et al., 2014), resulting in a high amount of high colored and often harmful waste (Alves de Lima et al., 2007). It is

\footnotetext{
* Corresponding author.

E-mail address: jcarvalho82@gmail.com (J.C. Cardoso).
}

estimated that 280,000 t of textile dyes are discharged in such industrial effluents annually worldwide (Jin et al., 2007), with complex aromatic molecular structures which are very stable and highly difficult to biodegrade (Azbar et al., 2004; Saratale et al., 2011). In addition, other organic and inorganic chemical reagents are found to be used in the textile sector, with both direct and indirect toxic effects on humans (Bakshi and Sharma, 2003; Moawad et al., 2003; Sponza, n.d.). Consequently, methods that can be used for the treatment of these effluents have by and large drawn great interest due to strict environmental legislation and high cost of water. Although several methods have been proposed for color removal, it is noteworthy that most of them have presented some underlying disadvantages (Banat et al., 1996; Gogate and Pandit, 2004; Malpass et al., 2007; Robinson et al., 2001).

Physical methods which are known to be the most widely used tend to, nonetheless, result in the formation of solid waste that requires further treatment, examples of which include membrane filtration, coagulation/flocculation, precipitation, flotation and adsorption (Gogate and Pandit, 2004). Biological processes include aerobic, anaerobic, and combinations of the two that can be subdivided into suspended and attached growth systems (Banat et al., 
1996; Gogate and Pandit, 2004). These processes are generally slower, requiring large storage areas and usually exhibit low efficiencies when it comes to color removal (Malpass et al., 2007; Robinson et al., 2001). Chemical processes are generally simpler in application and most of them rely on the formation of an oxidizing agent such as $\mathrm{H}_{2} \mathrm{O}_{2}, \cdot \mathrm{OH}$ or $\mathrm{O}_{3}$ (Gogate and Pandit, 2004).

It is undoubtedly fair to give the due merits to the meaningful contributions brought to the fore by a number of researchers through their studies vis-à-vis the combinations of ozone, oxygen, hydrogen peroxide, a wide range of homogenous and heterogeneous catalysts as well as (photo)catalysts in light/dark conditions for the oxidation of textile effluents (Azbar et al., 2004; Cardoso et al., 2015; Garcia et al., 2007; Gimeno et al., 2007; Gomes de Moraes et al., 2000; Poyatos et al., 2009; Santiago-Morales et al., 2012). These methodologies have been used for the treatment of contaminated water and wastewater to evaluate their capability in the decomposition of pollutants and to assess the treatment efficiencies of these combinations.

Ozone is a powerful oxidizing agent $\left(\mathrm{E}^{0}=2.07 \mathrm{~V}\right)$ with some applications in drinking water, swimming pools, industrial waters containing phenols and cyanides, among others (Hoigne, 1998). However, as ozone reacts selectively and slowly with organic compounds, it is sometimes combined with catalysts that can convert it into secondary oxidants, mainly to hydroxyl radicals known to be the most important and most reactive oxidants which are unselective by nature and capable of reacting with all types of solutes that can be subjected to oxidization (Hoigne, 1998). One of these combinations employs photoactivated semiconductors such as $\mathrm{TiO}_{2}$, resulting in a new advanced oxidation method called photocatalytic ozonation (Agustina et al., 2005). In this process, besides the generation of $\cdot \mathrm{OH}$ radicals by the $\mathrm{TiO}_{2}$ and the direct attack of ozone, the contaminant can be degraded by $\cdot \mathrm{OH}$ radicals produced in a sequence of reactions when $\mathrm{O}_{3}$ captures an electron of $\mathrm{TiO}_{2}$ conduction band. This process also minimizes the recombination of electron/hole pairs, improving the generation of hydroxyl radicals by oxidation through the holes at $\mathrm{TiO}_{2}$ valence band. This combination (allied to the resulting synergistic effects) is seen as a promising technique for the decomposition of refractory microorganisms and organic compounds in water. Recently, it has been noted that the combination of photoelectrocatalysis and ozone could significantly enhance the efficiency observed in the photocatalytic ozonation once photoelectrocatalysis is said to be capable of improving charge separation of $\mathrm{TiO}_{2}$ electron/hole pairs which consequently leads to more $\cdot \mathrm{OH}$ radicals (Bessegato et al., 2016).

The objective of this work is thus to design a versatile bubbling annular reactor operating with oxygen or ozone gases and a $\mathrm{TiO}_{2}$ nanotubes electrode as catalyst aiming at promoting the total decolorization of real wastewater from textile industries. The assessment of its efficiency was made comparing the following methods: photolysis, photocatalysis and photoelectrocatalysis with oxygen and ozone bubbling, as well as direct ozonation. The extent of the apparent color removal was evaluated by Platinum Cobalt $(\mathrm{Pt} / \mathrm{Co})$ scale color measurements (also referred to as the Hazen scale or APHA color). The electric energy per order $\left(E_{\mathrm{EO}}\right)$ was calculated for the different processes in order to compare and evaluate the color removal efficiency. Lastly, the extent of color removal and $E_{\mathrm{EO}}$ are compared with the reported levels presented in the literature.

\section{Experimental}

\subsection{Preparation of $\mathrm{TiO}_{2} \mathrm{NTS}$}

The $\mathrm{TiO}_{2}$ nanotubes arrays were produced by electrochemical anodization in an electrolyte composed of glycerol (90\%)/water (10\%) in the presence of $0.25 \% \mathrm{NH}_{4} \mathrm{~F}$ (Cardoso et al., 2010). Titanium pipes of $6 \mathrm{~cm}$ of diameter and $100 \mathrm{~cm}$ of length were firstly polished on different sandpapers and washed in isopropanol, acetone and deionized water for 10 times in each solvent, respectively. In sequence, this Ti pipe was inserted inside a PVC pipe of $10 \mathrm{~cm}$ of diameter and $110 \mathrm{~cm}$ of length and connected to a power supply as anode. In the center, a DSA electrode ${ }^{\circledR}$ (De Nora company) of $3 \mathrm{~cm}$ of width and $100 \mathrm{~cm}$ of length was positioned and connected as cathode. The system was filled up with the electrolyte and the anodization process was conducted for $50 \mathrm{~h}$ at $30 \mathrm{~V}$ using a Minipa MPL-1303 power supply. After this step, the sample was then washed in distilled water, dried in $\mathrm{N}_{2}$ gas and annealed at $450{ }^{\circ} \mathrm{C}$ for $1 \mathrm{~h}$ under atmospheric condition.

\subsection{Annular bubble reactor}

A versatile reactor was developed for real wastewater treatment using a glass vessel connected to a PVC pipe of varying lengths allowing the increasing of the effluent volume. A pipe with $145 \mathrm{~cm}$ length and $10.2 \mathrm{~cm}$ of diameter was then used to treat $12 \mathrm{~L}$ of effluents for direct ozonation and $8.5 \mathrm{~L}$ for treatment under irradiation as a result of the volume occupied by the glass tube using $100 \mathrm{~W}$ UV-B lamp Lightech ( $315 \mathrm{~nm}$ and $0.128 \mathrm{~mW} \mathrm{~cm}^{-2}$ ) inserted in the center of the reactor.

Four techniques were used to evaluate the performance of the reactor during the treatment among them including direct ozonation; photolysis; photocatalysis and photoelectrocatalysis, and their representative schemes have been depicted in Fig. 1. Gas diffusers were positioned at the bottom of the glass base to generate small bubbles. Four gas diffusers were as such necessary to obtain a complete mix and homogeneity besides the improvement of mass transport and the hydrodynamics of the reactor.

\subsection{Ozone and oxygen gases}

Ozone and oxygen were the gases tested in these experiments. Oxygen was supplied from a cylinder containing dry oxygen $(99.9 \%$ purity). Ozone was generated by a corona discharge O3R model ID05 (Brazil) ozone generator from dry oxygen used as the feed gas. The ozone input rate varying between 1.11 and $2.91 \mathrm{~g} \mathrm{~h}^{-1}$ was delivered at a gas flow rate of $1-4 \mathrm{~L} \mathrm{~min}^{-1}$. The residual ozone in the water was measured by the Indigo method (Bader and Hoigné, 1981) and excess ozone was destroyed chemically after treatment.

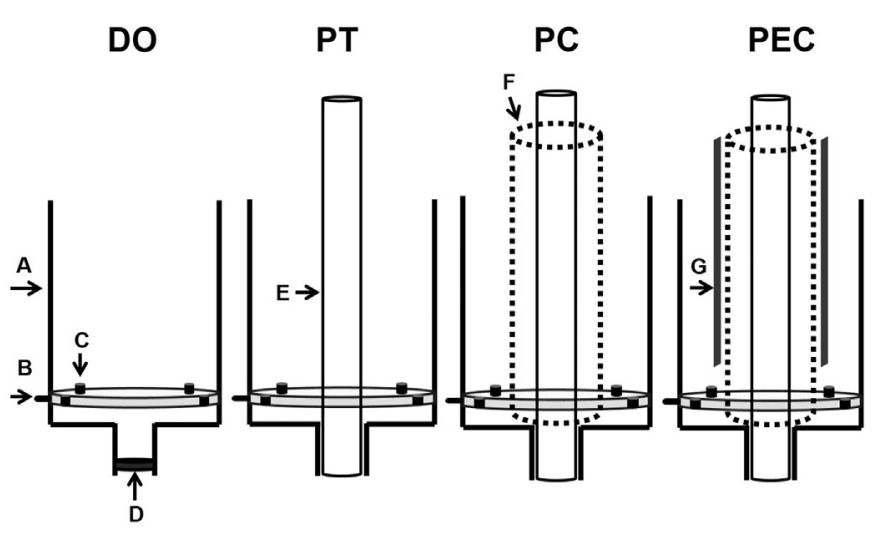

Fig. 1. Scheme of the reactor developed for the treatment of wastewater using DO, PT, PC and PEC processes, where: A: reactor glass wall; B: gas inlet; C: sintered glass diffusers for injecting $\mathrm{O}_{2} / \mathrm{O}_{3}$; D: rubber tip; E: glass tube to accommodate the UV-B $100 \mathrm{~W}$ lamp; F: cylindrical $\mathrm{TiO}_{2}$ nanotubes electrode (photoanode); G: DSA used as cathode. 


\subsection{Textile effluent}

The textile effluent was collected in flasks of $25 \mathrm{~L}$ in the final phase of treatment and kept under refrigeration at $10{ }^{\circ} \mathrm{C}$ until the end of the experiments so as to keep all the proprieties unchangeable. All the analyses were carried out without any change in the effluent. The values of all parameters, chemical and physicalchemical properties are shown in Table 1.

\subsection{Analysis of wastewater}

For all the treatment processes studied, $50 \mathrm{~mL}$ aliquots were taken out in pre-determined time of analysis and the sample was evaluated through measurements of $\mathrm{pH}$; total dissolved solids, conductivity (carried out using a pHmeter pHTEK); turbidity (Quimis turbidimeter), color of wastewater in Pt/Co units (Hanna Instruments model HI 83200 colorimeter); chemical oxygen demand (COD) (Macherey-Nagel model PF-3) and total organic carbon (TOC) (Shimadzu model TOC-V $\mathrm{V}_{\mathrm{CPN}}$ ).

\subsection{Decolorization process}

Several Advanced Oxidation Processes were tested to evaluate the performance of decolorization of real wastewater without any change in the original $\mathrm{pH}$ using a versatile bubble reactor. For photocatalytic and photoelectrocatalytic processes, a glass tube was inserted into the center of the reactor to accommodate a $100 \mathrm{~W}$ UV$\mathrm{B}$ narrow band lamp. In addition, a $\mathrm{TiO}_{2}$ NTs pipe was used as a photocatalyst and was positioned around the glass tube with a gap of $2 \mathrm{~cm}$. For photoelectrocatalytic degradation, two DSA sheets of $3 \mathrm{~cm} \times 100 \mathrm{~cm}$ (cathode) were inserted close to the anode and a different range of voltages were applied using a power supply (Minipa, model MPL-1303). The photolysis experiments were carried out using only the illumination from the UV-B lamp.

All these experiments were performed in the presence of $\mathrm{O}_{2}$ or $\mathrm{O}_{2} / \mathrm{O}_{3}$ mixture as bubbling gases. When the direct ozonation experiment was carried out, the reactor was adapted through the removal of the glass tube from the center, allowing an increase in the maximum volume of waste to $12 \mathrm{~L}$. All experiments were carried out in an isolated laboratory to avoid any contamination from ozone and percentages of color removal were calculated for each experiment.

\section{Results and discussion}

\subsection{Color removal using photolysis, photocatalysis and photoelectrocatalysis}

The color removal was evaluated using photolysis, photocatalysis and photoelectrocatalysis processes in a system where oxygen (flow of $1 \mathrm{~L} \mathrm{~min}^{-1}$ ) was used as stirring agent in the bubble reactor. The percentage of decolorization of the wastewater is shown in Fig. 2.

The performance of decolorization was practically negligible as only UV/Vis irradiation was used apart from the fact that only 3\% of color removal was obtained. In addition, a maximum of $7 \%$ of color removal was observed at the end of the process through photoelectrocatalysis or photocatalysis treatment. The low efficiency observed in both processes can be attributed to the high concentration of carbonate and bicarbonate ions. As a common rule, the first step in the waste treatment plant in the industry has to do with the $\mathrm{pH}$ correction in the wastewater that can assume different values ranging from 12 to 9 so as to render it suitable for biological treatment. Nevertheless, this correction is often carried out using $\mathrm{CO}_{2}$ gas to aid in the formation of carbonic acid, as shown in Eq. (1). The effluent of interest of the present work was collected from a jeans textile industry. The dyeing process involves the use of a great quantity of carbonate owing to the fact that reactive dyes are used in the process requiring alkaline medium (Karcher et al., 2001).

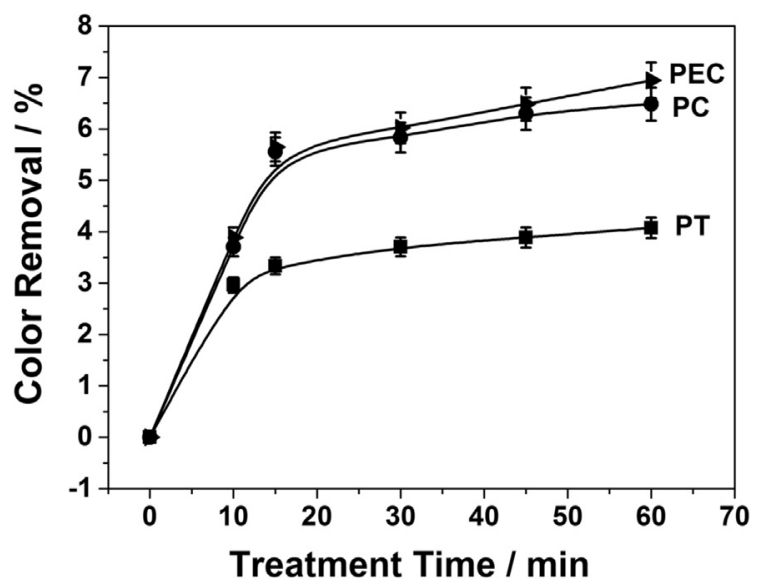

Fig. 2. Percentage of color removal of the textile wastewater for PT, PC and PEC processes at original $\mathrm{pH}$ and oxygen flow of $1 \mathrm{~L} \mathrm{~min}^{-1}$, using a UV-B narrow band lamp of $100 \mathrm{~W}$ for PT; UV-B lamp $+\mathrm{TiO}_{2}$ nanotubes for PC; and UV-B lamp $+\mathrm{TiO}_{2}$ nanotubes + DSA electrode $+2.0 \mathrm{~V}$ for PEC.

Table 1

Analytical screening of textile effluent before and after treatments using the annular bubble photoreactor (treatment time $=60$ min)

\begin{tabular}{|c|c|c|c|c|c|c|c|}
\hline \multirow[t]{2}{*}{ Processes } & \multicolumn{7}{|l|}{ Parameters } \\
\hline & Color/mg PtCo/L & Conductivity $/ \mathrm{mS} \mathrm{cm}^{-1}$ & TDS/ppt & Turbidity/NTU & OC/ppm & $\mathrm{IC} / \mathrm{ppm}$ & $\mathrm{COD} / \mathrm{ppm}$ \\
\hline $\begin{array}{l}\text { Original } \\
\mathrm{pH} 8+\mathrm{O}_{3}\end{array}$ & $1080 \pm 2.0$ & $9.24 \pm 2.1$ & $4.62 \pm 0.45$ & $2.77 \pm 2.3$ & $550 \pm 1.1$ & $611 \pm 1.5$ & $153 \pm 1.8$ \\
\hline PT & $22 \pm 2.1$ & $9.49 \pm 1.5$ & $4.74 \pm 0.89$ & $0.64 \pm 1.8$ & $521 \pm 1.7$ & $540 \pm 1.8$ & $108 \pm 2.1$ \\
\hline PC & $30 \pm 1.9$ & $8.81 \pm 1.9$ & $4.41 \pm 0.99$ & $1.35 \pm 2.3$ & $607 \pm 2.1$ & $640 \pm 1.8$ & $100 \pm 2.0$ \\
\hline PEC & $33 \pm 2.3$ & $9.49 \pm 2.1$ & $4.75 \pm 1.0$ & $2.32 \pm 2.4$ & $585 \pm 2.0$ & $610 \pm 1.5$ & $100 \pm 1.6$ \\
\hline OD & $46 \pm 1.8$ & $9.52 \pm 1.9$ & $4.76 \pm 0.95$ & $2.17 \pm 1.7$ & $509 \pm 2.4$ & $600 \pm 1.3$ & $100 \pm 1.7$ \\
\hline \multicolumn{8}{|l|}{$\mathrm{pH} 3+\mathrm{O}_{3}$} \\
\hline PT & $2.0 \pm 3.2$ & $4.12 \pm 1.7$ & $4.21 \pm 0.9$ & $2.39 \pm 2.1$ & $520 \pm 2.5$ & $0.440 \pm 2.1$ & $101 \pm 2.2$ \\
\hline PC & $7.0 \pm 3.0$ & $4.14 \pm 1.8$ & $4.19 \pm 1.1$ & $2.41 \pm 2.0$ & $515 \pm 2.6$ & $0.478 \pm 2.2$ & $103 \pm 2.0$ \\
\hline PEC & $10 \pm 3.1$ & $4.23 \pm 2.0$ & $4.15 \pm 1.1$ & $2.40 \pm 1.9$ & $502 \pm 2.5$ & $0.459 \pm 2.6$ & $102 \pm 2.0$ \\
\hline OD & $20 \pm 2.8$ & $4.19 \pm 1.9$ & $4.14 \pm 1.2$ & $2.42 \pm 1.9$ & $510 \pm 2.9$ & $0.412 \pm 2.3$ & $101 \pm 2.1$ \\
\hline
\end{tabular}

Where: TDS: total dissolved solids; OC: organic carbon; IC: inorganic carbon and COD: chemical oxygen demand. 
$\mathrm{CO}_{2}+\mathrm{H}_{2} \mathrm{O} \leftrightarrow \mathrm{H}_{2} \mathrm{CO}_{3} \leftrightarrow \mathrm{HCO}_{3}^{-}+\mathrm{H}^{+}$

Thus, the addition of salts such as carbonate and bicarbonate during the process of jeans fabrication for instance is found to be relatively high and for which coupled with the $\mathrm{CO}_{2}$ gas used for $\mathrm{pH}$ reduction may engender a higher concentration of inorganic carbon, measured in terms of carbonate/bicarbonate ions concentration. In the presence of these ions, the lifespan of hydroxyl radical is seen to be reduced as a result of the trapping of these oxidant species thereby leading to a slump in decolorization (Eqs. 2, 3).

$$
\begin{aligned}
& \mathrm{HCO}_{3}^{-}+\mathrm{OH}^{\bullet} \rightarrow \mathrm{CO}_{3}^{-}+\mathrm{H}_{2} \mathrm{O} \\
& \mathrm{CO}_{3}^{2-}+\mathrm{OH}^{\bullet} \rightarrow \mathrm{CO}_{3}^{-}+\mathrm{OH}^{-}
\end{aligned}
$$

Decolorization in acid $\mathrm{pH}$ was carried out in order to verify the effects on color reduction in the absence of carbonate and bicarbonate ions. Prior to the addition of sulfuric acid, the concentration of inorganic carbon was $611 \mathrm{mg} \mathrm{L}^{-1}$; upon reverting it to $\mathrm{pH} 3$ and undergoing $10 \mathrm{~min}$ of oxygen bubbling, the new inorganic carbon concentration was found to be $0.61 \mathrm{mg} \mathrm{L}^{-1}$ (Fig. 3). Under this new condition, the decolorization activity was studied and the results in the presence of oxygen are shown in Fig. 4.

When the experiments were carried out using only oxygen under $\mathrm{pH}$ 3.0, a partial decolorization of wastewater was observed for all the processes tested. Among the processes under investigation, the photoelectrocatalysis technique was the one that attained the highest color reduction after 60 min of reaction, then followed by photocatalysis and photolysis with $54.8 \%, 41.3 \%$ and $31.8 \%$, respectively. It is known from the literature that photoelectrocatalytic oxidation is more efficient than the photocatalysis given that photoelectrocatalysis reduces the recombination of photogenerated electron/hole pairs thus leading to the improvement in the production of $\mathrm{OH}$ radicals generated by the oxidation of water through the holes at the $\mathrm{TiO}_{2}$ valence band (Bessegato et al., 2015). By virtue of that the ozone gas was tested in order to evaluate the decolorization activity in real wastewater.

\subsection{Color removal by ozonation}

The color removal evaluated by the direct ozonation process was performed in the same system under $\mathrm{pH} 3$ and $\mathrm{pH} 8$ and using the following ozone input rates: $2.91 \mathrm{~g} \mathrm{O}_{3} \mathrm{~h}^{-1} ; 1.83 \mathrm{~g} \mathrm{O}_{3} \mathrm{~h}^{-1}$ and $1.11 \mathrm{~g}$ $\mathrm{O}_{3} \mathrm{~h}^{-1}$, delivered at gas flow rates of $1 \mathrm{~L} \mathrm{~min}^{-1} ; 2 \mathrm{~L} \mathrm{~min}^{-1}$ and $4 \mathrm{~L} \mathrm{~min}^{-1}$ Fig. 5 shows the decolorization activity in wastewater

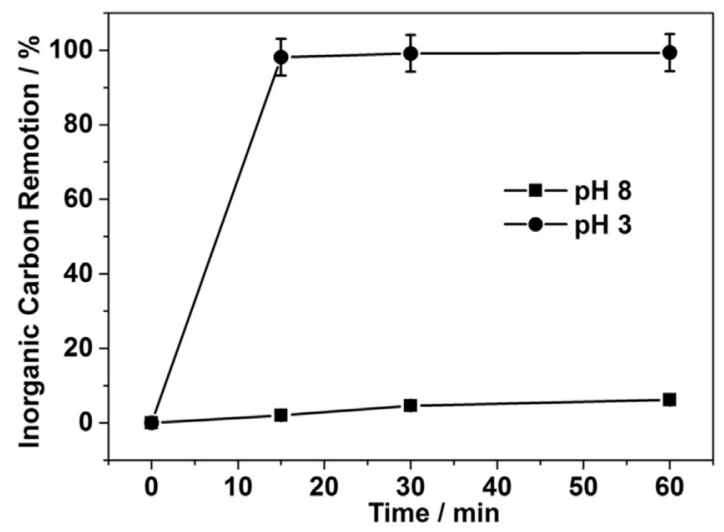

Fig. 3. Percentage of inorganic carbon removal from wastewater with $\mathrm{pH} 8$ and following its alteration to $\mathrm{pH} 3$ using concentrated sulfuric acid and bubbling with oxygen.

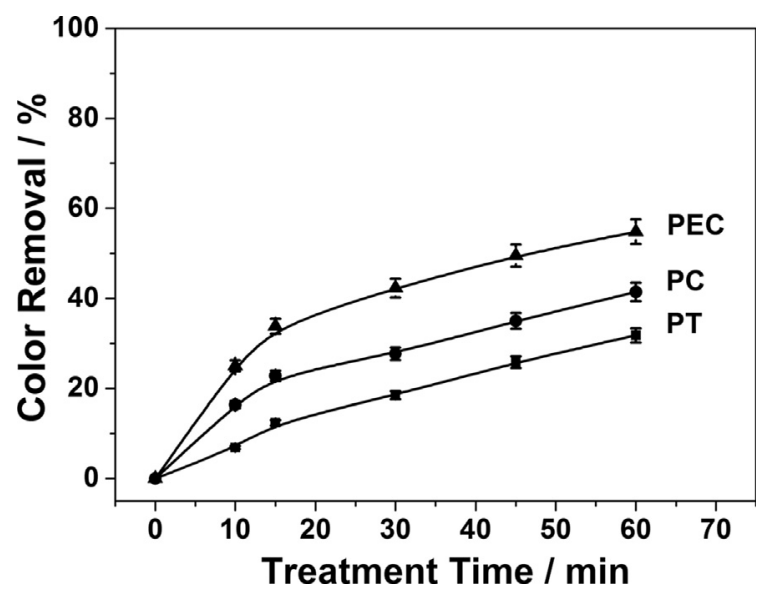

Fig. 4. Color removal of wastewater in $\mathrm{pH} 3$ for PT, PC, PEC and OD using oxygen as stirring gas under condition of: UV-B narrowband lamp of $100 \mathrm{~W}$ for PT; UV-B lamp $+\mathrm{TiO}_{2}$ nanotubes for PC; UV-B lamp $+\mathrm{TiO}_{2}$ nanotubes + DSA electrode $+2 \mathrm{~V}$ for PE, gas flow of $1.0 \mathrm{~L} \mathrm{~min}^{-1}$

accompanied with a change in these parameters.

According to Fig. 5A, comparing the two $\mathrm{pH}$ values $-\mathrm{pH} 3$ and $\mathrm{pH} 8$, the better performance of decolorization was registered under $\mathrm{pH}$ 3. More than $90 \%$ of performance was obtained under $\mathrm{pH} 3$ following the first $15 \mathrm{~min}$ of treatment while around $70 \%$ was found under $\mathrm{pH} 8$.

The best performance of decolorization is observed when the concentration of ozone is increased as depicted in Fig. 5B. These behavioral trends can be evidenced at the first 30 min of reaction, where, in greater concentration of $\mathrm{O}_{3}$ the color removal is seen to be higher than in lower $\mathrm{O}_{3}$ concentration. However, after 30 min of reaction, a minimal efficiency of color removal was registered and the effluent was almost decolorized in 45 and 60 min of treatment with similar performance. Thus, it is evident that the mass transference was primordial mainly at the first $30 \mathrm{~min}$ of reaction where the interactions between the organic compounds with $\mathrm{O}_{3}$ molecules reacted quickly.

The effect of total gas flow $\left(\mathrm{O}_{2} / \mathrm{O}_{3}\right)$ shown in Fig. $5 \mathrm{C}$ revealed that there was no significant influence on the decolorization of wastewater. The following handful of possibilities likely elucidate these results: (1) at a gas flow higher than $4 \mathrm{~L} \mathrm{~min}^{-1}$, the bubbles start a process of coalescence, becoming bigger and changing the original form, thus reducing the superficial contact area; (2) the mass transport is changed and a turbulence regime is identified, hence the interaction between the ozone and the pollutant molecule is undermined which thereby leads to a decrease in wastewater decolorization; and (3) the time of permanence of the ozone inside the reactor when the flow is increased is found to be shorter which consequently affects the performance.

Thus, the concentration and flow of ozone applied to evaluate the performance of real wastewater decolorization using ozone under the original $\mathrm{pH}$ and subsequently altering it to $\mathrm{pH} 3$ demonstrated to be a simple and fast process when it comes to the treatment of effluent from textile industry.

\section{Combination of ozone, photolysis, photocatalysis and photoelectrocatalysis in wastewater decolorization}

The combination of ozone, photolysis, photocatalysis and photoelectrocatalysis methods was carried out in order to evaluate the performance of wastewater decolorization under $\mathrm{pH} 3$. Under optimized conditions: direct ozonolysis: flow of $1 \mathrm{~L} \mathrm{~min} \mathrm{~min}^{-1}$ and ozone input rate of $2.91 \mathrm{~g} \mathrm{O}_{3} \mathrm{~h}^{-1}$ (where the residual ozone 

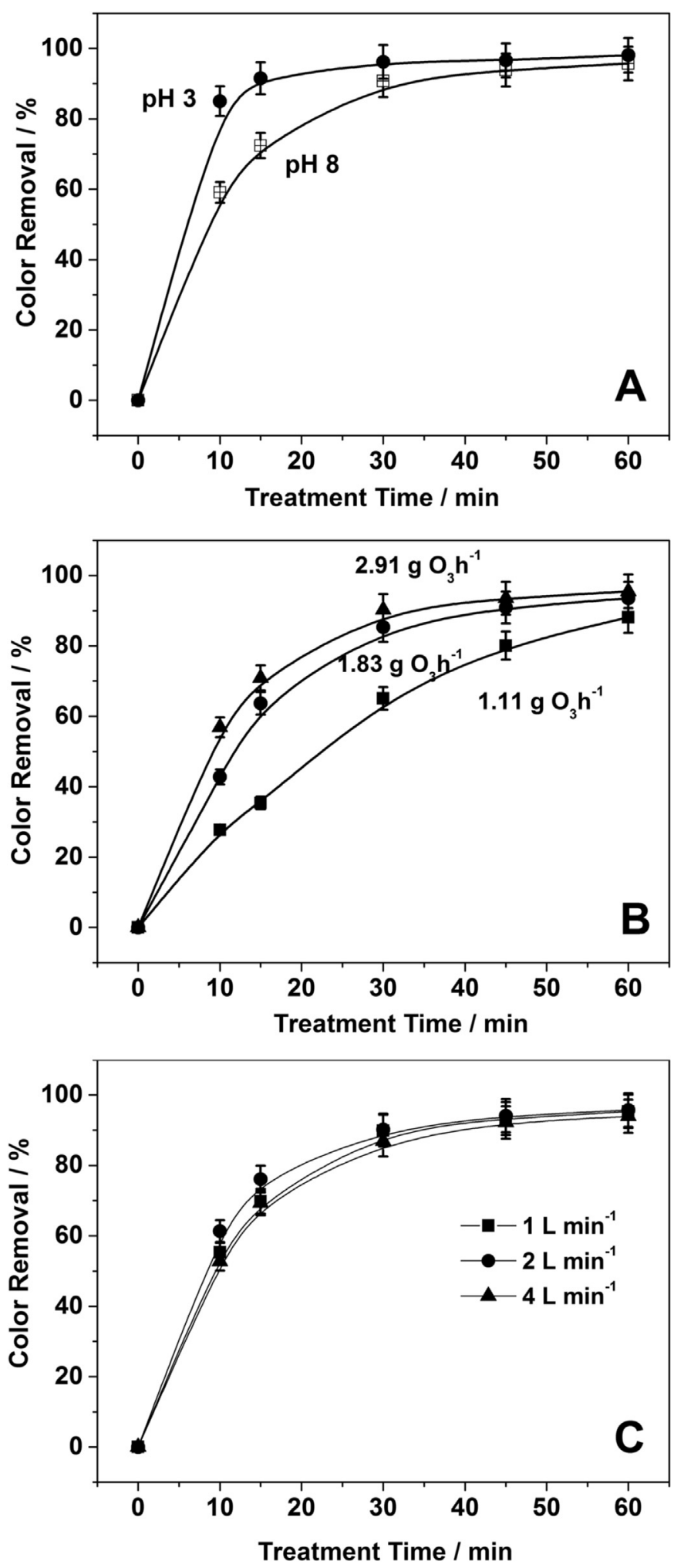

Fig. 5. Percentage of color removal by ozonation (A) at acidic and alkaline $\mathrm{pH}$ (ozone input rate of $2.91 \mathrm{~g} \mathrm{O}_{3} \mathrm{~h}^{-1}$ ); (B) at varying ozone input rates ( $\mathrm{pH} 8$ ); and (C) gas flow rates of delivering $\mathrm{O}_{3}(\mathrm{pH} 8)$.

concentration was calculated presenting the value of $6.48 \mathrm{mg}$ $\mathrm{O}_{3} \mathrm{~L}^{-1}$ ); photolysis: UVB lamp of $100 \mathrm{~W}$; photocatalysis: UVB lamp of $100 \mathrm{~W}$ and $\mathrm{TiO}_{2}$ nanotubes and photoelectrocatalysis: UVB lamp of $100 \mathrm{~W}, \mathrm{TiO}_{2}$ nanotubes and $2.0 \mathrm{~V}$ applied. Concurrently, the study

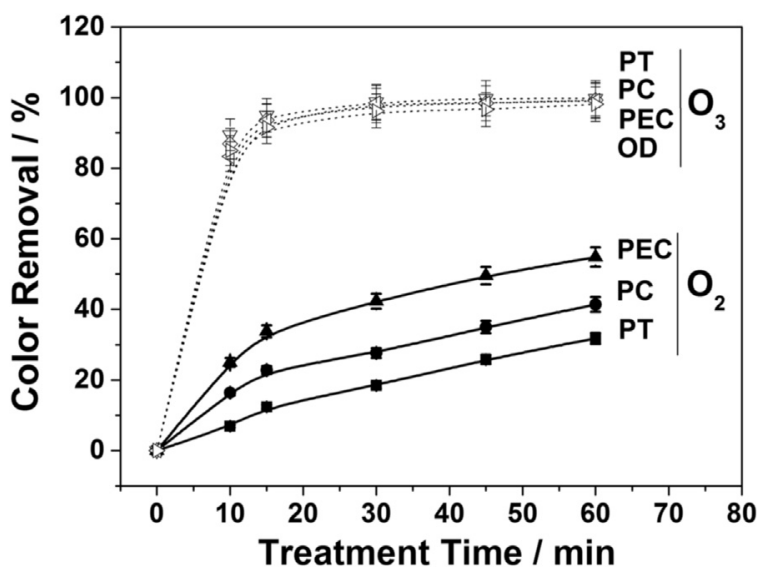

Fig. 6. Color removal of wastewater under $\mathrm{pH} 3$ for PT, PC, PEC and DO using oxygen and ozone as bubbling gas under condition of: UV-B narrowband lamp of $100 \mathrm{~W}$ for PT; UV-B lamp $+\mathrm{TiO}_{2}$ nanotubes for PC; UV-B lamp $+\mathrm{TiO}_{2}$ nanotubes + DSA electrode $+2 \mathrm{~V}$ for PEC; Ozone input rate of $2.91 \mathrm{~g} \mathrm{O}_{3} \mathrm{~h}^{-1}$ (gas flow of $1.0 \mathrm{~L} \mathrm{~min}^{-1}$ ).

using oxygen as stirring gas was carried out and the percentage of color removal is shown in Fig. 6.

Nevertheless, upon changing the stirring agent to ozone, this performance is found to undergo a significant hike with the results showing a decolorization superior to $90 \%$ following $15 \mathrm{~min}$ of treatment for all the processes evaluated: $95.0 \%, 93.6 \%, 93.4 \%$ and 91.5\% for photolysis, photocatalysis, photoelectrocatalysis and direct ozonation processes, respectively.

In comparison, following the first 15 min of treatment, a huge difference was observed in the percentage of decolorization between the two gases used: $82.6 \%, 70.6 \%$ and $57.7 \%$ for photolysis, photocatalysis and photoelectrocatalysis processes, respectively. When carbonate/bicarbonate ions are removed from the effluent, more hydroxyl radicals are found to be formed which oxidize the organic compounds present in the wastewater. However, the complexity of the waste tends to be high while the color is seen to be partially degraded.

This behavior can be explained owing to a synergistic effect occurring when ozone is combined with photocatalysis and photoelectrocatalysis generating a higher amount of hydroxyl radicals in a mechanism referred to as photocatalytic ozonation. In these systems, ozone can react with a photogenerated electron at $\mathrm{TiO}_{2}$ conduction band, producing ozonide radicals, which can generate hydroxyl radicals in acidic media (Eqs. (4)-(7)). In addition, under UV irradiation, ozone can react with water generating $\mathrm{H}_{2} \mathrm{O}_{2}$, another very strong oxidizing agent (Eq. (8)).

$$
\begin{aligned}
& \mathrm{TiO}_{2}+\mathrm{h} u \rightarrow \mathrm{TiO}_{2}-\mathrm{e}^{-}+\mathrm{TiO}_{2}-\mathrm{h}^{+} \\
& \mathrm{O}_{3}+\mathrm{TiO}_{2}-\mathrm{e}^{-} \rightarrow \mathrm{O}_{3}^{-} \\
& \mathrm{O}_{3}^{-} \bullet+\mathrm{H}^{+} \rightarrow \mathrm{HO}_{3}^{\bullet} \\
& \mathrm{HO}_{3}^{\bullet} \rightarrow \mathrm{O}_{2}+\mathrm{OH}^{\bullet} \\
& \mathrm{O}_{3}+\mathrm{H}_{2} \mathrm{O}+\mathrm{h} \mathrm{h} \rightarrow \mathrm{H}_{2} \mathrm{O}_{2}+\mathrm{O}_{2}
\end{aligned}
$$

Thus, the presence of ozone coupled with the oxidative elevated potential propel the improvement of decolorization and when associated with other advanced oxidation processes tend to diminish the treatment time. It is evident that under $\mathrm{pH} 8.0$ the contribution of ozone is to a larger extent essential and all the AOPs are impaired owing to the presence of carbonate and bicarbonate ions. However, under $\mathrm{pH} 3.0$ and in the absence of these ions, the 
participation of photolysis, photocatalysis and photoelectrocatalysis is found to be quite considerable.

There are two mechanisms through which ozone can degrade organic pollutants: direct electrophilic attack (Eq. (9)) and indirect attack by which hydroxyl radicals are formed (Eqs. (10) and (11)) (Agustina et al., 2005; Bessegato et al., 2016).

$\mathrm{O}_{3}+\mathrm{R} \rightarrow \mathrm{Rox}$

$\mathrm{O}_{3}+\mathrm{OH}^{-} \rightarrow \mathrm{OH}^{\bullet}+\left(\mathrm{O}_{2}^{\bullet} \leftrightarrow \mathrm{HO}_{2}^{\bullet}\right)$

$\mathrm{OH}^{\bullet}+\mathrm{R}^{\bullet} \rightarrow \operatorname{Rox}$

The mechanism of ozone action depends on the solution $\mathrm{pH}$, which significantly influences ozone decomposition in water. Basic $\mathrm{pH}$ causes an increase in ozone decomposition for $\cdot \mathrm{OH}$ radicals. Under $\mathrm{pH}<3$, direct ozone attack known as ozonolysis takes place.

The decomposition of ozone can be significantly lowered in the presence of hydroxyl radicals scavengers as a result of the following reactions [Eqs. (12)-(16)]:

$$
\begin{aligned}
& \mathrm{HO}^{\bullet}+\mathrm{O}_{3} \rightarrow \mathrm{O}_{2}+\mathrm{HO}_{2}^{\bullet} \mathrm{k}_{2}=3.0 \times 10^{9} \mathrm{M}^{-1} \mathrm{~s}^{-1} \\
& \mathrm{HO}^{\bullet}+\mathrm{HCO}_{3}^{-} \rightarrow \mathrm{OH}^{-}+\mathrm{HCO}_{3}^{\bullet} \mathrm{k}_{2}=1.5 \times 10^{7} \mathrm{M}^{-1} \mathrm{~s}^{-1} \\
& \mathrm{HO}^{\bullet}+\mathrm{CO}_{3}^{2-} \rightarrow \mathrm{OH}^{-}+\mathrm{CO}_{3}^{-} \mathrm{k}_{2}=4.2 \times 10^{8} \mathrm{M}^{-1} \mathrm{~s}^{-1} \\
& \mathrm{HO}^{\bullet}+\mathrm{H}_{2} \mathrm{PO}_{4}^{-} \rightarrow \mathrm{OH}^{-}+\mathrm{H}_{2} \mathrm{PO}_{4}^{\bullet} \mathrm{k}_{2}<10^{5} \mathrm{M}^{-1} \mathrm{~s}^{-1} \\
& \mathrm{HO}^{\bullet}+\mathrm{HPO}_{4}^{2-} \rightarrow \mathrm{OH}^{-}+\mathrm{H}_{2} \mathrm{PO}_{4}^{-} k_{2}<10^{7} \mathrm{M}^{-1} \mathrm{~s}^{-1}
\end{aligned}
$$

Reactions of ozone with organic matter usually lead to the formation of aldehydes and carboxylic acids, both of which do not react with ozone. This is a critical limitation of ozonation as total mineralization of organic matter cannot be achieved. Furthermore, oxidative reactions with ozone are relatively slow and selective; therefore, if the ozonation reaction is not satisfactorily fast, radical processes such as hydroxyl radicals have to be implemented.

The association of these different processes used in wastewater decolorization in order to improve its performance cannot be linked independently as a sum of each technique (Agustina et al., 2005). This behavior was explained by Bessegato and collaborators (Bessegato et al., 2016), where close-related results were registered for the degradation of an acid dye using a similar system of treatment. A synergistic effect was observed when ozone was combined with photocatalysis or photoelectrocatalysis, remarkably improving the efficiency of degradation comparing to the sum of the processes conducted separately. High decolorization rates were obtained in all the processes with ozone as a result of the fast selective attack of ozone to $\mathrm{C}=\mathrm{C}$ bonds, though ozone was unable to remove organic carbon efficiently. However, when ozone was combined with photoelectrocatalysis, very high rates of organic carbon removal were obtained, as hydroxyl radicals mainly provide the attack to these molecules. $\mathrm{OH}$ radicals can be generated by the $\mathrm{TiO}_{2}$ irradiation and through ozone conversion via electron or UV reactions; they are unselective and are capable of mineralizing organic contaminants most effectively. Table 1 compares each parameter of real wastewater after $60 \mathrm{~min}$ of treatment by the different techniques in $\mathrm{pH} 3$ and $\mathrm{pH} 8$ using ozone gas. The values of the parameters using oxygen gas (data not shown) did not promote significant improvements in the effluent decolorization performance.

Based on the afore-mentioned observations, real wastewater from textile industry can be said to be extremely complex given the numberless processes and steps involved until the formation of the final product. The presence of several compounds and substances as well as dyes and pigments in the same solution pose as an underlying challenge that lingers on the development of systems involving the treatment of huge volumes of water. Thus, methodologies of treatment whose performance are faster, relatively more efficient and simpler are vitally necessary to ensure a high quality of water treatment while at the same time contributing towards protecting the environment.

\subsection{Energy consumption}

When choosing the best method for wastewater treatment, some significant factors should be taken under consideration including economy, effluent quality goals, ongoing regulatory framework, operationality, among others. However, the economic factor is often seen as the most relevant in this case and as AOPs are electric-energy-intensive, electric energy tends to account for the main operating cost (Bolton et al., 2001; Mehrjouei et al., 2014). The international union of pure and applied chemistry (IUPAC) has proposed figures-of-merit for advanced oxidation processes (AOPs) on the use of electrical energy (Bolton et al., 2001). Bolton and colleagues (Bolton et al., 2001) have established standard figuresof-merit for the comparison of energy consumption regardless of the nature of the system.

According to Malpass and collaborators (Malpass et al., 2007) who have applied these figures of merit for real textile effluent, the complex nature of this wastewater renders it difficult to know the exact dye composition and concentration. Interestingly enough though, measurements of the specific absorbance $\left(\mathrm{cm}^{-1}\right)$ of the chromophore bands are seen to be possible and are found to decrease with first-order dependence over the treatment. Eq. (17) shows the expression used to calculate the "electrical energy per order" $\left(E_{\mathrm{EO}} / \mathrm{kW} \mathrm{h} \mathrm{m}^{-3}\right.$ order $\left.^{-1}\right)$, where color unit is used instead of concentration. This, in essence, should not be a problem as the expression $\log \left(c_{\mathrm{i}} / c_{\mathrm{f}}\right)$ is dimensionless.

$E_{E O}=\frac{P \times t \times 1000}{V \times \log \left(\text { color }_{i} / \text { color }_{f}\right)}$

where $P$ stands for the rated power $(\mathrm{kW})$ of the oxidation system, $t$ being the treatment time $(\mathrm{h}), \mathrm{V}$ the treated volume $(\mathrm{L})$ and color $_{\mathrm{i}}$ and color $_{\mathrm{f}}$ the initial and final measurements in Pt/Co units. The rated power is known to be equal to the sum of the individual energy consumption of the ozonator, the lamp and the power supply. The consumption of each equipment (in Wh) was calculated measuring consumed current and the utility voltage during operation with a multimeter (Minipa ET-2042D). The lamp consumes 154.8 Wh, the power supply consumes $4.4 \mathrm{Wh}$ and the ozonator consumes $82.8 \mathrm{Wh}$ when it is producing $2.91 \mathrm{~g} \mathrm{O}_{3} \mathrm{~h}^{-1}$. Taking $9 \mathrm{~min}$ as the treatment time for the calculation of $\mathrm{E}_{\mathrm{EO}}$, Fig. 7 shows the $E_{\mathrm{EO}}$ values for the different systems.

For all the methods tested, at pH 3 we obtained a lower consumption of electric energy compared to the result found under $\mathrm{pH}$ 8. A maximum cost was obtained for photocatalysis, photoelectrocatalysis and photolysis followed by direct ozonation, with $8.36 ; 7.78 ; 7.28$ and $2.43 \mathrm{kWh} \mathrm{m}^{-3}$ order $^{-1}$, respectively under $\mathrm{pH} 3$. However, at $\mathrm{pH} 8$, a condition of higher consumption was observed for all the techniques under consideration. The electric energy per order calculated was: $12.41 ; 11.07 ; 11.07$ and $3.34 \mathrm{kWh} \mathrm{m} \mathrm{m}^{-3}$ order $^{-1}$, for photoelectrocatalysis, photocatalysis, photolysis and direct ozonation respectively.

Thus, in a critical analysis about decolorization, some aspects ought to be assessed in a particular way: (1) the wastewater performance of decolorization and (2) the total cost of treating this 


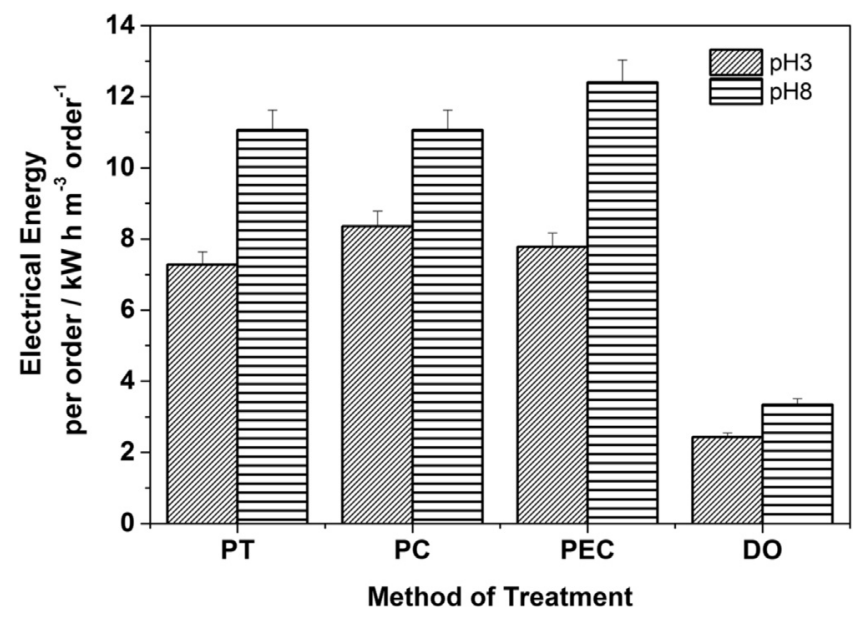

Fig. 7. Electrical energy per order $\left(\mathrm{kWh} \mathrm{m}^{-3}\right.$ order $\left.^{-1}\right)$ for the different methods of treatment evaluated.

waste. Although it is possible to obtain decolorization at similar times of treatment under both $\mathrm{pH} 3$ and $\mathrm{pH} 8$ (with a slight advantage for $\mathrm{pH} 3$ ), the cost of reducing the $\mathrm{pH}$ for treatment in acid solution as well as neutralizing it after the treatment and releasing the effluent into rivers or sewage station are also vital factors that deem to be given the due consideration. In this situation, direct ozonation was the technique whose performance was comparably the most desirable owing to the following few aspects: higher percentage of decolorization; short time of treatment; low energetic cost; higher volumes of waste to be treated; simplicity of the system and possibility to use both acidic and alkaline solutions.

A few studies in the literature have employed this useful figure of merit for real textile effluent in order to compare the costs of different treatment methods. Malpass and collaborators (Malpass et al., 2007) have studied the decolorization of real textile effluent by constant current electrolysis in a flow-cell using a DSA ${ }^{\circledR}$ electrode and the effect of the chloride concentration, where $E_{\mathrm{EO}}$ varied from 30 to $500 \mathrm{kWh} \mathrm{m}^{-3}$ order $^{-1}$ depending on the parameters applied. In another similar study of Malpass et al.(Malpass et al., 2008), the effect of electrode composition on the decolorization was investigated and $E_{\mathrm{EO}}$ varied from 26 to $58 \mathrm{kWh} \mathrm{m}^{-3}$ order $^{-1}$. Daneshvar and colleagues (Daneshvar et al., 2005) have also reported having evaluated the photooxidative decolorization of four textile dyestuffs (Acid Orange 7, Acid Orange 8, Acid Orange 52 , Acid Blue 74) by $\mathrm{UV} / \mathrm{H}_{2} \mathrm{O}_{2}$. These textile dyes could be treated effectively with the $\mathrm{UV} / \mathrm{H}_{2} \mathrm{O}_{2}$ process with $E_{\mathrm{EO}}$ values between 0.4 and $5 \mathrm{kWh} \mathrm{m}^{-3}$ order $^{-1}$ depending on the initial concentrations of dyes and $\mathrm{H}_{2} \mathrm{O}_{2}$. These values of energy per order $\left(E_{\mathrm{EO}} / \mathrm{kWh} \mathrm{m}^{-3}\right.$ order $^{-1}$ ) for color removal are considerably lower than those presented in the literature for textile effluents due to the complexity nature of real effluents.

Comparing these $E_{\mathrm{EO}}$ values with those calculated in this work, the ozonation of textile effluent presented very lower values compared to electrolysis and to the studies that reported the treatment of textile dye solutions, which did not have the same complexity.

Considering a pilot reactor of treatment, this change can be easily effected. Oddly enough though, analyzing continuum volumes from industry where the volume of waste generated is in an order of cubic meters, this change bears a great demerit when it comes to changing the $\mathrm{pH}$, where huge volumes of acids and specific tanks and pumps will be necessary to structure the system adequately. All these issues merit a considerable thought prior to taking the decision regarding which $\mathrm{pH}$ is to be applied in the treatment process.

\section{Conclusion}

A bubbling reactor with ozone system was tested for the treatment of real textile wastewater. The method was found to promote more than $90 \%$ of decolorization after 15 min of reaction. The presence of carbonate and bicarbonate ions considerably reduced the performance of the processes based on the generation of hydroxyl radicals (AOPs) such as photocatalysis and photoelectrocatalysis thanks to the scavenging reactions of ${ }^{\bullet} \mathrm{OH}$ radicals by carbonate or bicarbonate ions, which were confirmed through tests in acidic and alkaline $\mathrm{pH}$ values. The ozonation process demonstrated to be more efficient under both $\mathrm{pH}$ values evaluated due to the reaction capability via direct attack and the possibility of forming hydroxyl radicals. Given the reduced energy consumption, direct ozonation presented lower values of electric energy per order as well as similar decolorization performance compared to the combination of ozone with photocatalysis or photoelectrocatalysis. Thus, the simple reactor developed was capable of promoting a total decolorization of wastewater, while ozonation treatment was found to be relatively faster, simpler, more efficient, yet at the same time cheaper besides its capacity to treat a huge volume of textile effluent. Our findings are an important step vis-à-vis the evaluation of an efficient and simple method for the treatment of real and complex industrial effluent. As the textile industry consumes very large volume of water, ozonation is an alternative to the conventional treatments (such as membranes), and can collaborate towards the reduction of the costs with water, as the treated water could be recycled in the industry. It is also undoubtedly advantageous for the environment as the effluent when subjected to adequate treatment helps to reduce the deplorable impact and the irreparable hazards that it poses to human health, animals and to other living organisms when it is released into rivers.

\section{Acknowledgements}

The authors deem it a great honor and privilege to extend their heartfelt gratitude to the Brazilian Research Agencies - FAPESP (Process no. 2014/03679-7 and 2015/18109-4) and CNPq (Process Number 446245/2014-3), for the financial support granted in the course of this research. We are also grateful to our English reviewer - Jefferson Brian Newmann A. for the earnest proofreading and editing services provided towards improving the English language content of this article.

\section{References}

Agustina, T.E., Ang, H.M., Vareek, V.K., 2005. A review of synergistic effect of photocatalysis and ozonation on wastewater treatment. J. Photochem. Photobiol. C Photochem. Rev. 6, 264-273. http://dx.doi.org/10.1016/ j.jphotochemrev.2005.12.003.

Alves de Lima, R.O., Bazo, A.P., Salvadori, D.M.F., Rech, C.M., de Palma Oliveira, D., de Aragão Umbuzeiro, G., 2007. Mutagenic and carcinogenic potential of a textile azo dye processing plant effluent that impacts a drinking water source. Mutat. Res. 626, 53-60. http://dx.doi.org/10.1016/j.mrgentox.2006.08.002.

Azbar, N., Yonar, T., Kestioglu, K., 2004. Comparison of various advanced oxidation processes and chemical treatment methods for COD and color removal from a polyester and acetate fiber dyeing effluent. Chemosphere 55, 35-43. http:// dx.doi.org/10.1016/j.chemosphere.2003.10.046.

Bader, H., Hoigné, J., 1981. Determination of ozone in water by the indigo method. Water Res. 15, 449-456. http://dx.doi.org/10.1016/0043-1354(81)90054-3.

Bakshi, D.K., Sharma, P., 2003. Genotoxicity of textile dyes evaluated with ames test and rec-assay. J. Environ. Pathol. Toxicol. Oncol. 22, 10. http://dx.doi.org/ 10.1615/JEnvPathToxOncol.v22.i2.30.

Banat, I.M., Nigam, P., Singh, D., Marchant, R., 1996. Microbial decolorization of textile-dyecontaining effluents: a review. Bioresour. Technol. 58, 217-227. http://dx.doi.org/10.1016/S0960-8524(96)00113-7.

Bessegato, G.G., Cardoso, J.C., da Silva, B.F., Zanoni, M.V.B., 2016. Combination of photoelectrocatalysis and ozonation: a novel and powerful approach applied in acid yellow 1 mineralization. Appl. Catal. B Environ. 180, 161-168. http:// dx.doi.org/10.1016/j.apcatb.2015.06.013. 
Bessegato, G.G., Guaraldo, T.T., de Brito, J.F., Brugnera, M.F., Zanoni, M.V.B., 2015. Achievements and trends in photoelectrocatalysis: from environmental to energy applications. Electrocatalysis. http://dx.doi.org/10.1007/s12678-015-02599.

Bolton, J.R., Bircher, K.G., Tumas, W., Tolman, C.A., 2001. Figures-of-merit for the technical development and application of advanced oxidation technologies for both electric- and solar-driven systems (IUPAC Technical Report). Pure Appl. Chem. 73, 627-637. http://dx.doi.org/10.1351/pac200173040627.

Cardoso, J.C., Lizier, T.M., Zanoni, M.V.B., 2010. Highly ordered TiO2 nanotube arrays and photoelectrocatalytic oxidation of aromatic amine. Appl. Catal. B Environ. 99, 96-102. http://dx.doi.org/10.1016/j.apcatb.2010.06.005.

Cardoso, J.C., Lucchiari, N., Zanoni, M.V.B., 2015. Bubble annular photoeletrocatalytic reactor with $\mathrm{TiO} 2$ nanotubes arrays applied in the textile wastewater. J. Environ. Chem. Eng. 3, 1177-1184. http://dx.doi.org/10.1016/j.jece.2015.04.010.

Daneshvar, N., Aleboyeh, A., Khataee, A.R., 2005. The evaluation of electrical energy per order EEO for photooxidative decolorization of four textile dye solutions by the kinetic model. Chemosphere 59, 761-767. http://dx.doi.org/10.1016/ j.chemosphere.2004.11.012.

Garcia, J.C., Oliveira, J.L., Silva, A.E.C., Oliveira, C.C., Nozaki, J., de Souza, N.E., 2007. Comparative study of the degradation of real textile effluents by photocatalytic reactions involving UV/TiO2/H2O2 and $\mathrm{UV} / \mathrm{Fe} 2+/ \mathrm{H} 2 \mathrm{O} 2$ systems. J. Hazard. Mater 147, 105-110. http://dx.doi.org/10.1016/j.jhazmat.2006.12.053.

Ghaly, A.E., Ananthashankar, R., Alhattab, M., Ramakrishnan, V.V., 2014. Production, characterization and treatment of textile effluents: a critical review. J. Chem. Eng. Process Technol. 05, 1-18. http://dx.doi.org/10.4172/2157-7048.1000182.

Gimeno, O., Rivas, F.J., Beltrán, F.J., Carbajo, M., 2007. Photocatalytic ozonation of winery wastewaters. J. Agric. Food Chem. 55, 9944-9950. http://dx.doi.org/ $10.1021 / \mathrm{jf072167i}$.

Glaze, W.H., Kang, J.-W., Chapin, D.H., 1987. The chemistry of water treatment processes involving ozone, hydrogen peroxide and ultraviolet radiation. Ozone Sci. Eng. 9, 335-352. http://dx.doi.org/10.1080/01919518708552148.

Gogate, P.R., Pandit, A.B., 2004. A review of imperative technologies for wastewater treatment II: hybrid methods. Adv. Environ. Res. 8, 553-597. http://dx.doi.org/ 10.1016/S1093-0191(03)00031-5.

Gomes de Moraes, S., Sanches Freire, R., Durán, N., 2000. Degradation and toxicity reduction of textile effluent by combined photocatalytic and ozonation processes. Chemosphere 40, 369-373. http://dx.doi.org/10.1016/S0045-6535(99) 00239-8.

Hoigne, J., 1998. Chemistry of aqueous ozone and transformation of pollutants by ozonation and advanced oxidation processes. In: Hrubec, J. (Ed.), The Handbook of Environmental Chemistry: Quality and Treatment of Drinking Water II.
Springer-Verlag, Berlin Heidelberg, pp. 83-141. http://dx.doi.org/10.1007/978 3-540-68089-5.

Jin, X.-C., Liu, G.-Q., Xu, Z.-H., Tao, W.-Y., 2007. Decolorization of a dye industry effluent by Aspergillus fumigatus XC6. Appl. Microbiol. Biotechnol. 74, 239-243. http://dx.doi.org/10.1007/s00253-006-0658-1.

Karcher, S., Kornmüller, A., Jekel, M., 2001. Screening of commercial sorbents for the removal of reactive dyes. Dye. Pigment. 51, 111-125. http://dx.doi.org/10.1016/ S0143-7208(01)00066-3.

Malpass, G.R.P., Miwa, D.W., Machado, S.A.S., Motheo, A.J., 2008. Decolourisation of real textile waste using electrochemical techniques: effect of electrode composition. J. Hazard. Mater 156, 170-177. http://dx.doi.org/10.1016/ j.jhazmat.2007.12.017.

Malpass, G.R.P. Miwa, D.W., Mortari, D.A., Machado, S.A.S, Motheo, A. , 2007 Decolorisation of real textile waste using electrochemical techniques: effect of the chloride concentration. Water Res. 41, 2969-2977. http://dx.doi.org/ 10.1016/j.watres.2007.02.054.

Mehrjouei, M., Müller, S., Möller, D., 2014. Catalytic and photocatalytic ozonation of tert-butyl alcohol in water by means of falling film reactor: kinetic and cost-effectiveness study. Chem. Eng. J. 248, 184-190. http://dx.doi.org/10.1016 j.cej.2014.03.047.

Moawad, H., El-Rahim, W.M.A., Khalafallah, M., 2003. Evaluation of biotoxicity of textile dyes using two bioassays. J. Basic Microbiol. 43, 218-229. http:/ dx.doi.org/10.1002/jobm.200390025.

Poyatos, J.M., Muñio, M.M., Almecija, M.C., Torres, J.C., Hontoria, E., Osorio, F., 2009 Advanced oxidation processes for wastewater treatment: state of the art. Water. Air. Soil Pollut. 205, 187-204. http://dx.doi.org/10.1007/s11270-009-0065-1.

Robinson, T., McMullan, G., Marchant, R., Nigam, P., 2001. Remediation of dyes in textile effluent: a critical review on current treatment technologies with a proposed alternative. Bioresour. Technol. 77, 247-255. http://dx.doi.org/ 10.1016/S0960-8524(00)00080-8.

Santiago-Morales, J., Gómez, M.J., Herrera, S., Fernández-Alba, A.R., García-Calvo, E., Rosal, R., 2012. Oxidative and photochemical processes for the removal of galaxolide and tonalide from wastewater. Water Res. 46, 4435-4447. http:/ dx.doi.org/10.1016/j.watres.2012.05.051.

Saratale, R.G., Saratale, G.D., Chang, J.S., Govindwar, S.P., 2011. Bacterial decolorization and degradation of azo dyes: a review. J. Taiwan Inst. Chem. Eng. 42 138-157. http://dx.doi.org/10.1016/j.jtice.2010.06.006.

Sponza, D.T., n.d. Necessity of toxicity assessment in turkish industrial discharges (examples from metal and textile industry effluents). Environ. Monit. Assess. 73, 41-66. doi:10.1023/A:1012663213153. 